\title{
Recuperação e revitalização de área de preservação permanente com projeto de parque linear na cidade de Rochedo, MS: estudo de caso
}

\section{Recovery and revitalization of permanent preservation area with project of linear park in the city of Rochedo, MS: \\ case study}

Recuperación y revitalización de área de preservación permanente con proyecto de parque linear en la ciudad de Rochedo, MS: estudio de caso

Giovanna Ferreira Campos ${ }^{1}$

Bruna lara de Oliveira Cuevas ${ }^{2}$ Leandro Manoel Alves de Sousa ${ }^{3}$ Rocheli Carnaval Cavalcanti ${ }^{4}$

${ }^{1}$ Acadêmica do curso de Agronomia da Universidade Católica Dom Bosco (UCDB). E-mail: giferreira.agro@gmail.com, Orcid: http://orcid.org/0000-0002-7311-0898

${ }^{2}$ Acadêmica do curso de Agronomia da Universidade Católica Dom Bosco (UCDB). E-mail: agrobrunaiara@hotmail.com, Orcid: http://orcid.org/0000-0002-6467-2266

${ }^{3}$ Mestre em Irrigação e Drenagem pela Universidade Estadual Júlio de Mesquita Filho (Unesp). Possui MBA em Administração pelo Instituto Mauá de Tecnologia. Graduado em Ciências Agronômicas pela Unesp. Professor na Universidade Católica Dom Bosco (UCDB).E-mail: leandro.sousa@ucdb.br, Orcid: http://orcid.org/0000-0003-0052-7542

${ }^{4}$ Doutoranda em Ciências Ambientais e Sustentabilidade Agropecuária pela Universidade Católica Dom Bosco (UCDB). Mestre em Engenharia Civil pela Universidade Federal de Santa Catarina (UFSC). Graduada em Engenharia Civil pela Universidade Federal de Mato Grosso do Sul (UFMS). Professora na UCDB. Coordenadora do curso de Pós-Graduação (lato sensu) em Gestão Ambiental EAD. E-mail: rocheli@ucdb.br, Orcid: http://orcid.org/0000-0002-6634-4215 
Giovanna Ferreira CAMPOS; Bruna lara de Oliveira CUEVAS; Leandro Manoel Alves de SOUSA; Rocheli Carnaval CAVALCANTI

Resumo: O presente estudo tem como intenção a criação de um parque linear em área de preservação permanente urbana. Para autorização do uso da área como objeto de estudo, foi necessário realizar consulta ao Novo Código Florestal e ao Plano Diretor. Após delimitação do espaço de estudo, a vegetação existente foi posicionada em uma planta baixa. Durante o mapeamento, observou-se a presença de declives e analisaram-se possíveis modos de utilização do local pela comunidade. A partir dessas informações, dividimos a área para melhor posicionamento das plantas e das estruturas a serem implementadas. O projeto paisagístico utiliza-se de plantas que se adaptam melhor ao ambiente e de estruturas que proporcionem lazer e recreação. A implantação do parque tem como finalidade proteger a área de preservação permanente, criando um ambiente que aproxima a população da educação ambiental e fornece um local para a prática de esporte, elevando o bem-estar da comunidade.

Palavras-chave: área verde; urbanização; paisagismo; Cerrado; Plano Diretor.

\begin{abstract}
The present study intends to assess the creation of a linear park in an area of permanent urban preservation. In order to authorize the use of the area as a subject of study, it was necessary to consult the New Forest Code and the Master Plan. After delimiting the space, the existing vegetation in a low plant was positioned. During the process of mapping, it was observed the presence of slopes, and possible ways of using the site by the community were analyzed. Based on this information we divided the area to better position the plants and the structures. The landscaping project uses plants that will adapt better to the environment and assessed structures that will provide leisure and recreation. The purpose of the implementation of the park is to protect the permanent preservation area, creating an environment that brings the population closer to environmental education and provides a venue for sports, enhancing thus the well-being of the community.
\end{abstract}

Keywords: green area; urbanization; landscaping; the Cerrado; Master Plan.

Resumen: Este presente estudio tiene como intención la creación de un parque lineal en área de preservación permanente urbana. Para la autorización del uso de esa área como objecto de estudio, fue necesario realizar consulta al Nuevo Código Forestal y al Plan Director. Después de la delimitación del espacio, se ubicó la vegetación existente en una planta baja. Durante el mapeo se observó la presencia de inclinaciones y posibles modos de utilización del local por la comunidad. A partir de esas informaciones, dividimos el área para mejor posicionamiento de las plantas y estructuras. El proyecto paisajístico se utiliza de plantas que se adaptan mejor al ambiente y de estructuras que proporcionen actividades de ocio y recreación. La implantación del parque tiene como finalidad proteger el área de preservación permanente, creando un ambiente que aproxima la población de la educación ambiental y proporciona un lugar para la práctica del deporte, elevando el bienestar de la comunidad.

Palabras clave: zona verde; urbanización; paisajismo; Cerrado; Plan Maestro. 


\section{INTRODUÇÃO}

A cidade de Rochedo, MS, foi fundada às margens do Rio Aquidauana, sem planejamento na urbanização e não levando em consideração a preservação do meio ambiente, assim, prejudicando a vegetação ciliar e a proteção do rio. Atualmente há grande interesse em revitalizar e recuperar as áreas de preservação permanente (APP) urbanas, que são protegidas por lei e, por isso, a intervenção tem de ser autorizada pela Lei 12.651/2012 (Novo Código Florestal). Em muitos casos, os municípios acabam por utilizar essas áreas de APP como área de interesse social, através de parques lineares ou outras formas de uso, porém a elaboração do projeto do parque linear precisa estar em conformidade com o plano diretor da cidade, uma vez que a área verde urbana deve estar prevista nas Leis de Zoneamento Urbano e Uso do Solo do Município.

O objetivo deste estudo de caso foi a elaboração de um projeto para a recuperação e revitalização da APP com a proposta de criação de um parque linear adjacente ao Rio Aquidauana, em conformidade com o Plano Diretor do município de Rochedo, MS.

\section{REFERENCIAL TEÓRICO}

\section{1. Área verde urbana}

Um dos modos de incluir a natureza às áreas urbanas é por meio de áreas verdes, que, segundo Cavalheiro et al. (1999), são um espaço livre constituído predominantemente por vegetação, atendendo a três propósitos básicos: ecológico-ambiental, estético e de lazer, a fim de servir aos indivíduos e propiciar o uso e as condições para recreação. Deste modo, espaços como praças, jardins e parques urbanos podem ser denominados de áreas verdes.

No Art. 3, inciso XX, da Lei n. 12.651/12 (BRASIL, 2012), entende-se por área verde urbana os espaços, públicos ou privados, com predomínio de vegetação, preferencialmente nativa, natural ou recuperada, previstos no Plano Diretor, nas Leis de Zoneamento Urbano e Uso do Solo do Município, indisponíveis para construção de moradias, destinados aos propósitos de 
recreação, lazer, melhoria da qualidade ambiental urbana, proteção dos recursos hídricos, manutenção ou melhoria paisagística, proteção de bens e manifestações culturais.

Londe e Mendes (2014) explicam que as áreas verdes trazem inúmeros benefícios à vida urbana, proporcionando equilíbrio com o meio ambiente e, como consequência, melhores condições climáticas, além de beneficiar o solo, o ar e a água. Há também vantagens na qualidade de vida da população, melhorando seu desenvolvimento social, assim como saúde física e mental, a qual enaltece o bem-estar dos moradores. Tudo isso devido ao contato do homem com a natureza e a disponibilidade de atividades de lazer e recreação. A ausência de áreas verdes nas cidades demonstra a falta de planejamento urbano do governo, como também o descaso com a saúde física e mental da população.

Costa e Colesanti (2011) esclarecem ainda que esses locais oferecem um aumento de status e valor, sendo o valor relacionado aos preços imobiliários e o status com a tranquilidade, o lazer e o bem-estar.

Um ponto muito importante na implantação destas áreas é o envolvimento da população na criação do projeto; sem a participação dela, seria impossível atender aos objetivos do espaço, ocasionando abandono e esquecimento. É importante para a conservação e o uso do local que as expectativas e os desejos dos frequentadores sejam atendidos, para que, por meio da utilização, se desenvolva um laço afetivo com o lugar (COSTA et al., 2011).

\section{2 Área de preservação permanente em áreas urbanas}

A maioria das cidades surge e se desenvolve a partir de rios, afinal, eles são canais de comunicação e possibilitam o abastecimento de água potável. Desta maneira, todas as atividades realizadas nos cursos d'água deveriam se enquadrar nas normas que protegem a APP. Entretanto, no dia a dia, essas normas são na maioria das vezes desconsideradas em áreas urbanas, o que ocasiona graves danos ambientais, como assoreamento do corpo d'água, enchentes e deslizamentos, causando grandes riscos para os seres vivos. Diante disso, as APPs são áreas vigorosamente supervisionadas perante a 
legislação, em que a vegetação deve ser mantida intacta, buscando diretamente a preservação dos recursos hídricos, do solo e da biodiversidade. Mesmo tendo a legislação tão rígida, a APP pode ser utilizada se for para utilidade pública ou interesse social (ARAÚJO, 2002).

Há uma ligação direta entre a preservação das áreas permanentes e o uso social, deixando clara a necessidade da valorização dos recursos ambientais, de preservar as APPs e conscientizar a população a usá-la de forma correta (MATTOS et al., 2007).

De acordo com Sousa Neto e Costa (2019), a educação ambiental (EA) é primordial para o desenvolvimento sustentável, devendo estar presente de forma compreensível em todos os lugares para todas as pessoas, tendo um propósito de colaborar com o conhecimento. Há diversos métodos para se ministrar aulas de EA, realizando-as em locais de APPs, parques, praças e instituições de ensino em níveis fundamental, médio e superior.

Tirar o homem do seu local de conforto faz com que a compreensão da importância que a natureza tem seja mais ampla do que em qualquer sala de aula. Isto tornará o ser humano apto ao uso consciente do meio ambiente (CARVALHO, 2017).

\section{APRESENTAÇÃO DO CASO}

\subsection{Base legal}

Em consequência de o tipo de vegetação ser protegido por lei, é preciso que as medidas tomadas para aplicação do projeto sejam feitas em concordância com a legislação. De acordo com a Lei n. 12.651/12, conhecida como Novo Código Florestal:

Art. 8 A intervenção ou a supressão de vegetação nativa em Área de Preservação Permanente somente ocorrerá nas hipóteses de utilidade pública, de interesse social ou de baixo impacto ambiental previsto nesta Lei.

Entende-se por interesse social, segundo o Novo Código Florestal, Art. 3, inciso IX, alínea c, como: "c) a implantação de infraestrutura pública destinada a esportes, lazer e atividades educacionais e culturais ao ar livre em áreas urbanas e rurais consolidadas, observadas as condições estabelecidas nesta Lei" (BRASIL, 2012). 
A descrição de interesse social muito se assemelha ao estabelecimento de área verde urbana, que corresponde à premissa do projeto, sendo então perfeitamente cabível perante a legislação a utilização da APP. Segundo a classificação de área verde urbana encontrada na Lei 12.651/12, Art. 3, inciso XX, o local precisa estar previsto no Plano Diretor, nas Leis de Zoneamento Urbano e Uso do Solo do Município.

O Plano Diretor está previsto no Art. 182 da Constituição Federal de 1988 e tem como objetivo ordenar o pleno desenvolvimento das funções da cidade e garantir o bem-estar dos seus, sendo obrigatório apenas para cidades com mais de vinte mil habitantes. Apesar de o município de Rochedo não dispor de vinte mil, desde o ano de 2014 ele possui seu Plano Diretor (PD), também conhecido como Lei Complementar n. 34/14 (ROCHEDO, 2014).

A área de estudo está situada na Macrozona de Adensamento Restrito, que, conforme o Art. 35, inciso III do PD, compreende as áreas não urbanizadas e as de preservação permanente, de acordo com legislação federal pertinente, e destina-se à ocupação controlada.

O Anexo III do PD representa, por intermédio do mapa do município, as delimitações de macrozoneamento e áreas especiais (Figura 1). Observase que as áreas adjacentes ao rio são identificadas como Área Especial de Interesse Ambiental, que é estabelecida no Art. 42:

Art. 42 Ficam instituídas as Áreas Especiais - AE, compostas por porções do território que exigem tratamento especial na definição de parâmetros reguladores de usos e ocupação do solo, podendo se sobrepor às Macrozonas Urbanas, e se classificam como:

$\S 1$ o Nas Áreas Especiais de Interesse Ambiental, instituídas por esta Lei, serão permitidos os seguintes usos: uni residencial, parques, áreas de recreação e lazer, viveiros e hortos. (ROCHEDO, 2014). 
Recuperação e revitalização de área de preservação permanente com projeto de parque linear na cidade de Rochedo, MS: estudo de caso

Figura 1 - Macrozoneamento e áreas especiais de interesse

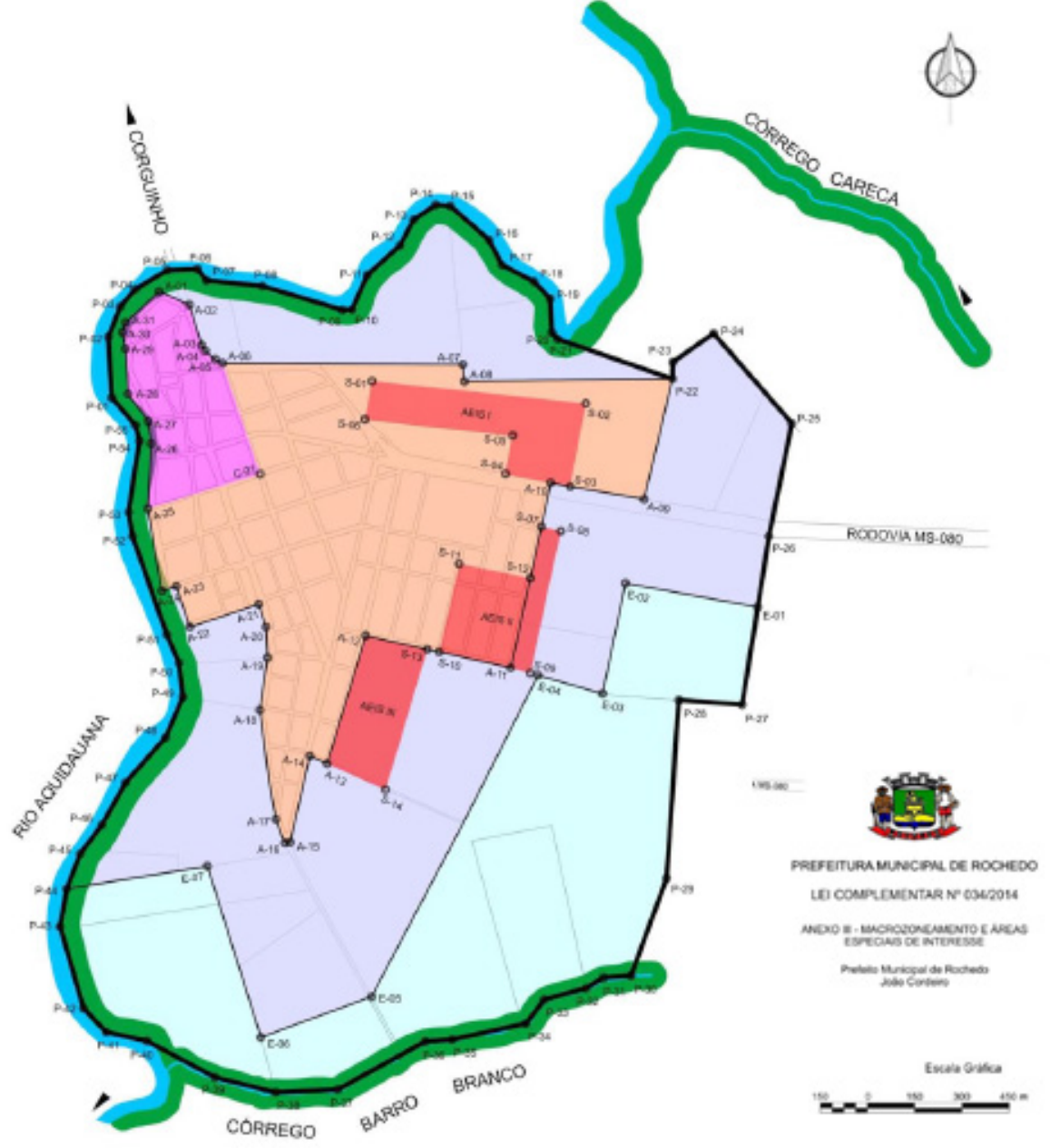

LE G E N A

\begin{tabular}{ll}
\hline & Macrozona de Adensamento Prioritário - MZ1 \\
& Macrozona de Adensamento Secundário - MZ2 \\
& Macrozona de Adensamento Restrito - MZ3 \\
& Área Especial de Interesse Cultural - AEIC - MZ1 \\
$\square$ & Área Especial de Interesse Social - AEIS - MZ1 e MZ2 \\
$\square \quad$ Área Especial de Interesse Ambiental - AEIA - MZ1,MZ2 e MZ3 \\
$\quad$ Perimetro Urbano \\
\end{tabular}

Fonte: Plano Diretor, anexo III (ROCHEDO, 2014). 
Com base no Art. 42 do PD, parágrafo 1ํ, pode-se afirmar que a proposta do projeto está em concordância com o Art. 3, inciso XX, do Novo Código Florestal, já que o local do projeto tem permissão para os seguintes usos: parques, recreação e lazer.

\section{2 Área de estudo}

Localizada no sul da região Centro Norte de Mato Grosso do Sul, na microrregião de Campo Grande, a cidade de Rochedo está entre as coordenadas geográficas 19057'11" S e uma longitude 5453'33” W. O município é banhado pelo Rio Aquidauana, que nasce na Serra de Maracaju, com uma extensão total de $620 \mathrm{~km}^{1}$.

Segundo a menção anterior, a cidade teve seus primeiros moradores, imigrantes nordestinos, em 1931, os quais foram atraídos pelo garimpo de diamantes. Por este motivo, a cidade se desenvolveu em torno do Rio Aquidauana. Com o rápido crescimento populacional, o município não teve sua expansão planejada, desenvolvendo-se de forma desordenada e tornando-se insustentável economicamente, prejudicando o rio e a mata ciliar.

A área de estudo está localizada na Avenida Afonso de Araújo Passos, entre as ruas Campo Grande e Duque de Caxias. O local é tradicionalmente utilizado pelos moradores para lazer e recreação (pesca, banho, confraternização, entre outros).

O bioma presente é classificado como Cerrado, o qual é considerado o segundo maior do país, representando $23 \%$ do território brasileiro. Entre as classificações de vegetações, enquadra-se como formações florestais, possuindo predominantemente espécies arbóreas compostas de dossel contínuo. As formações florestais podem ser divididas em mata ciliar, mata de galeria, mata seca e cerradão (RIBEIRO et al., 1983).

As matas classificadas como de galeria e ciliares são aquelas associadas a cursos da água. Na área do projeto, há predominância da mata de galeria, por ter características de vegetação que segue rios de pequeno e médio porte e forma corredores fechados sobre o curso d'água. Há faixa de

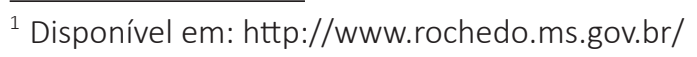


vegetação não florestal em ambos os lados possui como uma forte característica a mudança abrupta de suas formações para savânicas e campestres, as quais têm fisionomia perenifólia, em que as árvores não perdem suas folhas durante a estação seca, diferentemente da mata ciliar, na qual há diferentes graus de caducifólia (RIBEIRO; WALTER, 2008).

No local de estudo, encontram-se espécies nativas do Cerrado, como: ciriguela (Spondias purpurea); ingá (Inga diversas); goiaba (Psidium guajava); palmeiras-macaúba (Acrocomia aculeata).

O clima da cidade, de acordo com a classificação de Köppen e Geiger², é do tipo Aw, ou seja, clima tropical com estação seca de inverno. A pluviosidade média anual é de $1.438 \mathrm{~mm}$, o mês com menor precipitação é agosto, com $33 \mathrm{~mm}$; e de maior, janeiro, apresentando média de $241 \mathrm{~mm}$. A temperatura média do município é de $24,8^{\circ} \mathrm{C}$, sendo novembro o mês mais quente com temperatura média de $26,6^{\circ} \mathrm{C}$; as menores temperaturas estão em junho, que tem temperatura média de $21,8^{\circ} \mathrm{C}$. A variação média de temperatura durante o ano é de $4,8^{\circ} \mathrm{C}$.

\subsection{Proposta da criação de um parque linear}

Para as delimitações de área e perímetro, utilizou-se como ferramenta o Google Earth, em que ficou estabelecida uma área total de 5.667,25 m² e um perímetro de 565,70 m, ilustrados na Figura 2.

${ }^{2}$ Disponível em: http://pt.wikipedia.org/w/index.php?oldid=16801300 
Figura 2 - Delimitação de área de estudo no município de Rochedo, MS

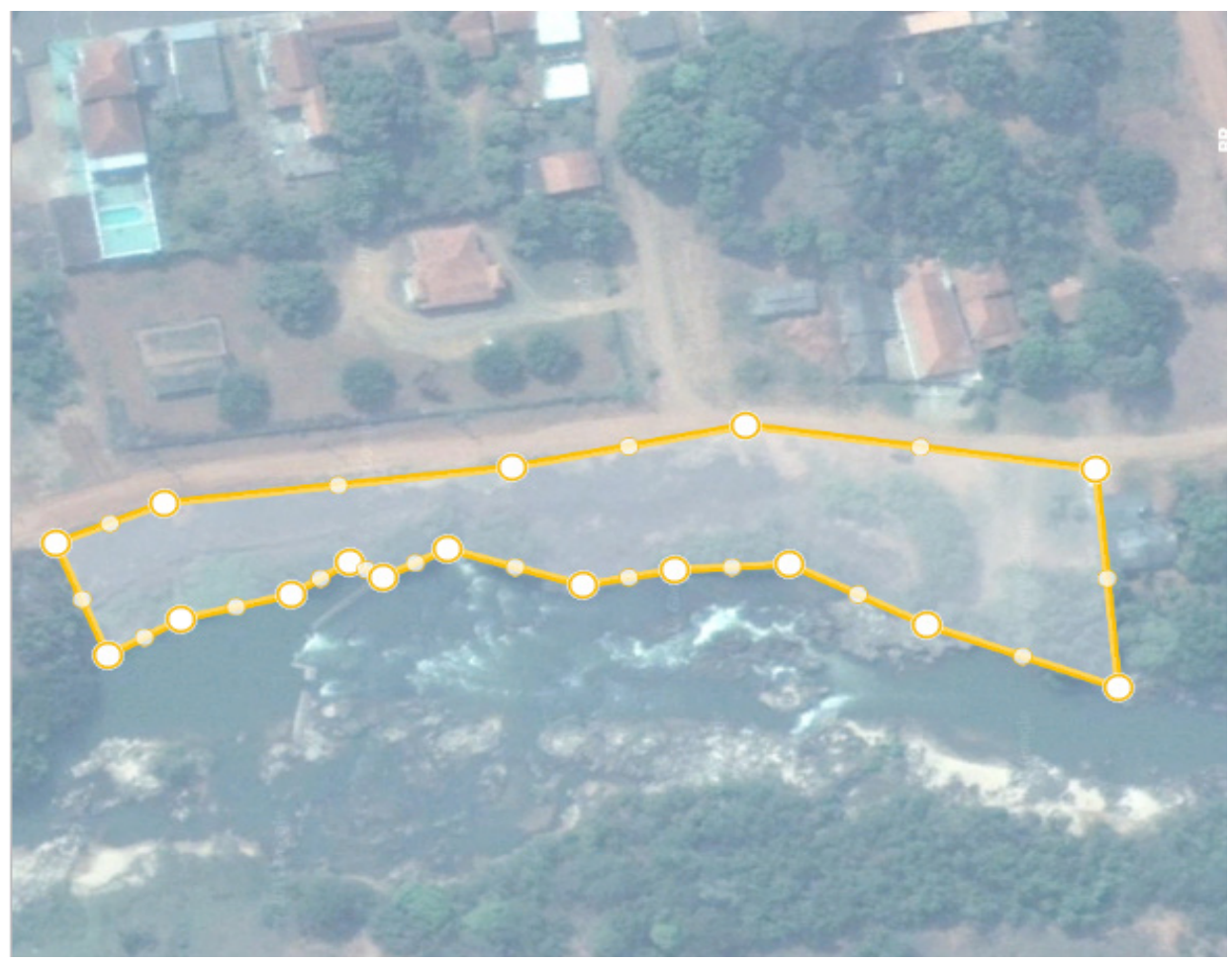

Fonte: Google Earth (dez. 2007).

Utilizando o mapa da cidade, foi possível isolar a área do projeto. Com trena e o mapa do local, impresso em folha A3, pudemos posicionar a vegetação presente para elaboração da planta baixa (Figura 3) com a vegetação existente. Durante o mapeamento, observou-se a presença de declividade na área e, como possivelmente o local é utilizado pelos moradores, desta forma, dividimos a área em quatro partes para o melhor posicionamento das plantas e da estrutura do parque. 
Figura 3 - Planta da situação atual

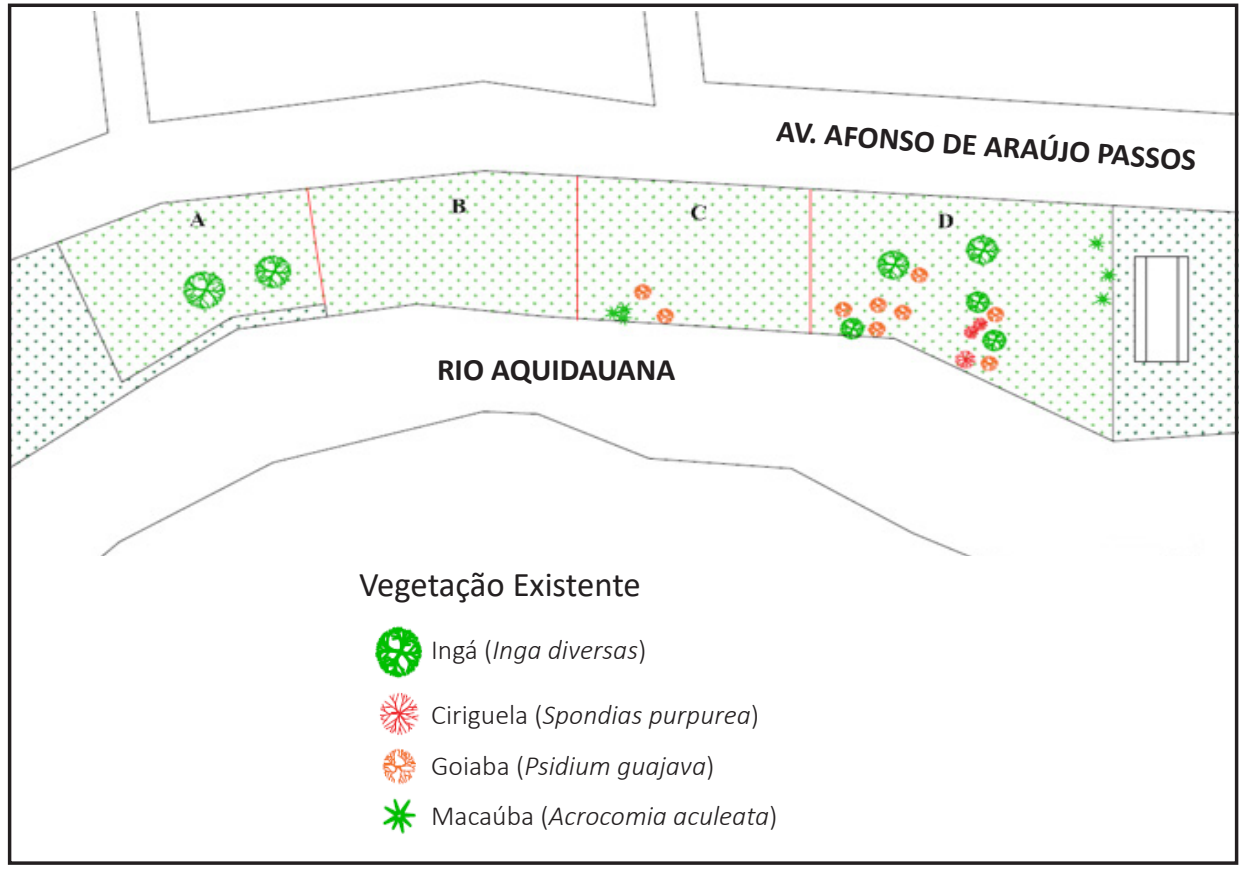

Fonte: Elaboração própria.

Para melhor compreensão, dividimos o espaço total em quatro áreas, sendo elas:

Área A - Tem sua largura delimitada entre a rua e a barragem de contenção de cheia (utilizada para evitar as enchentes). A área contém uma boa e uniforme cobertura de solo com forrageira da espécie Brachiaria spp e apenas duas árvores de ingá (Inga diversas) (Figura 4). 
Figura 4 - Área A (1 - Delimitação da rua à barragem de contenção; 2 e 3 - Árvores presentes na área)

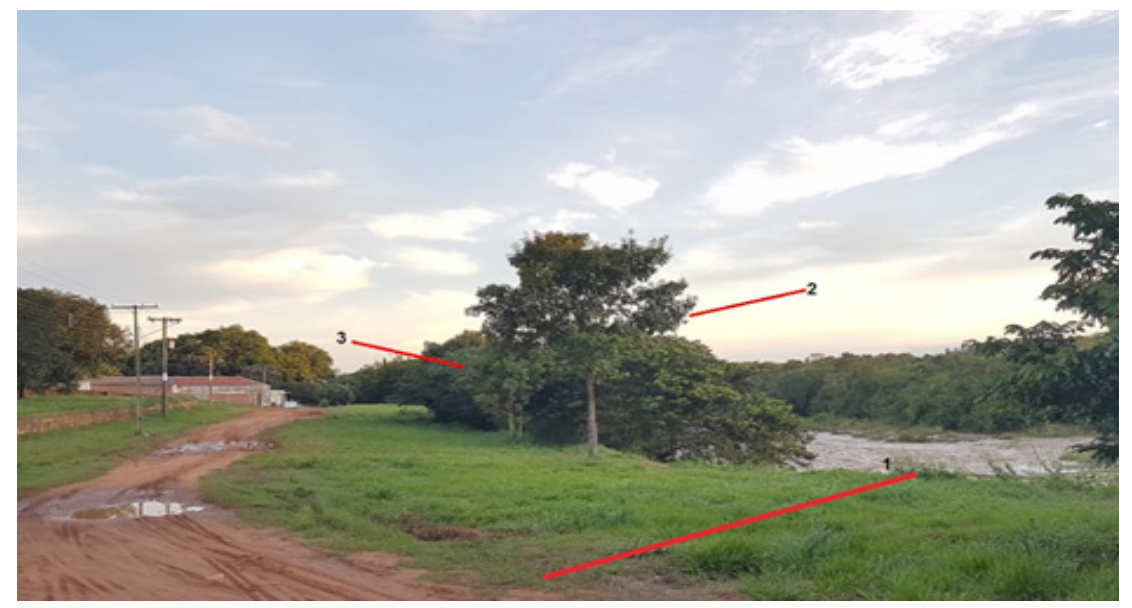

Fonte: Elaboração própria.

Haverá a implantação de árvores de porte médio a alto, inclusão de um playground infantil e uma academia ao ar livre (Figura 5).

Figura 5 - Ilustração do parque

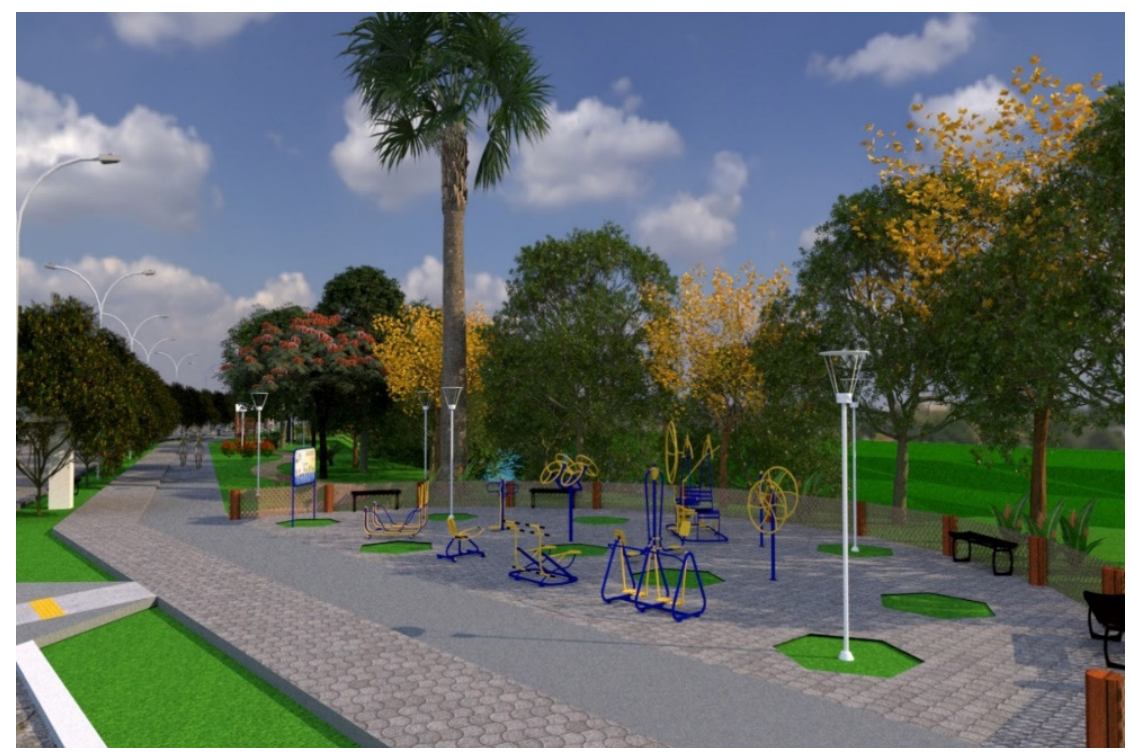

Fonte: Elaboração própria. 
Área B - Não há presença da barragem de contenção, podendo chegar até próximo ao rio. Sua largura se estende da rua até o rio, possuindo um forte declive. O local possui a mesma cobertura de forrageira da Área A e algumas espécies de palmeira-macaúba (Figura 6).

Figura 6 - Área B

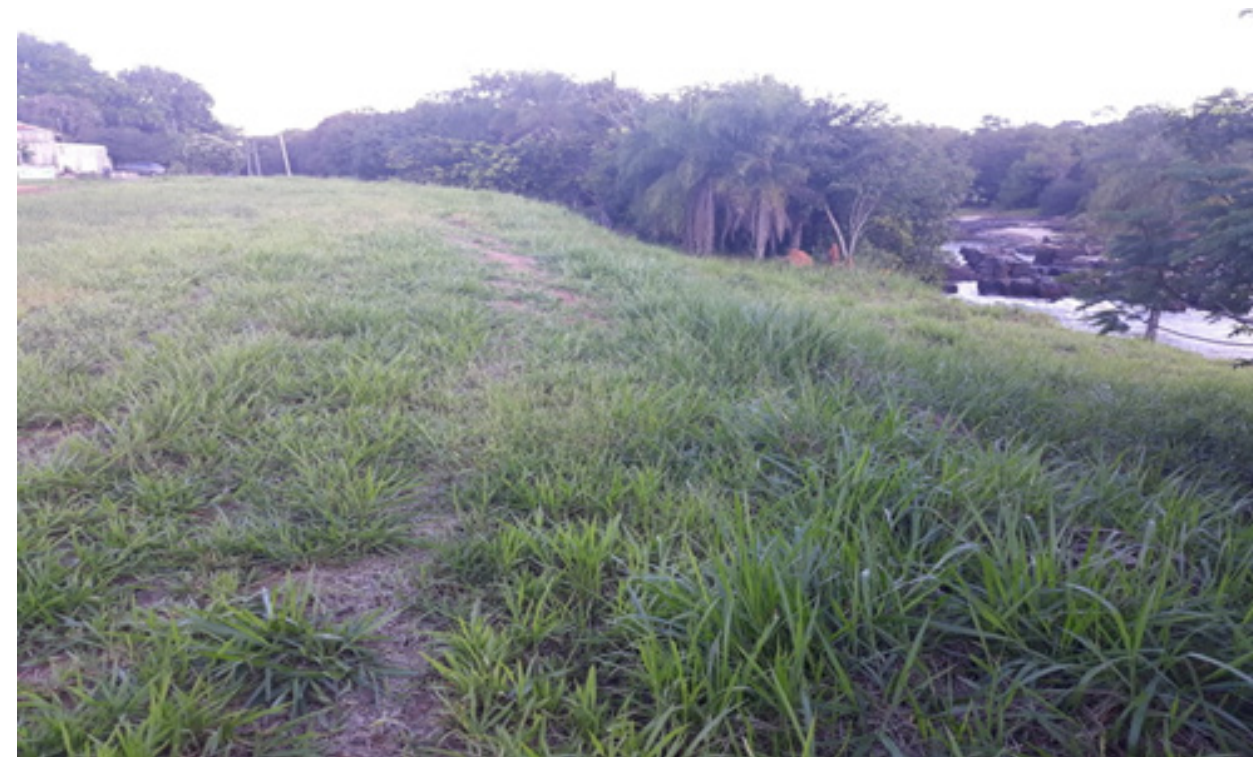

Fonte: Elaboração própria.

Para aproveitar o declive, a sugestão é a estruturação de um mirante (Figura 7). 
Figura 7 - Ilustração do deck

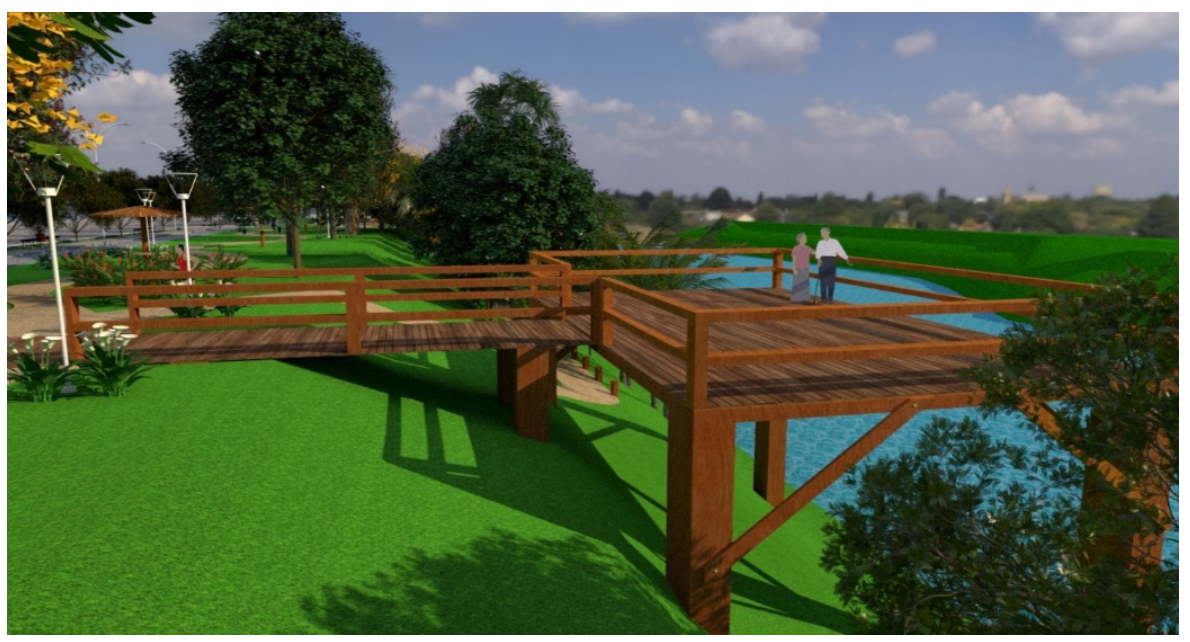

Fonte: Elaboração própria.

Área C-É semelhante à Área B, porém a área do declive (Figura 8) que dá acesso ao rio possui algumas árvores nativas da espécie goiaba (Psidium guajava) e palmeira-macaúba (Acrocomia aculeata).

Figura 8 - Área C

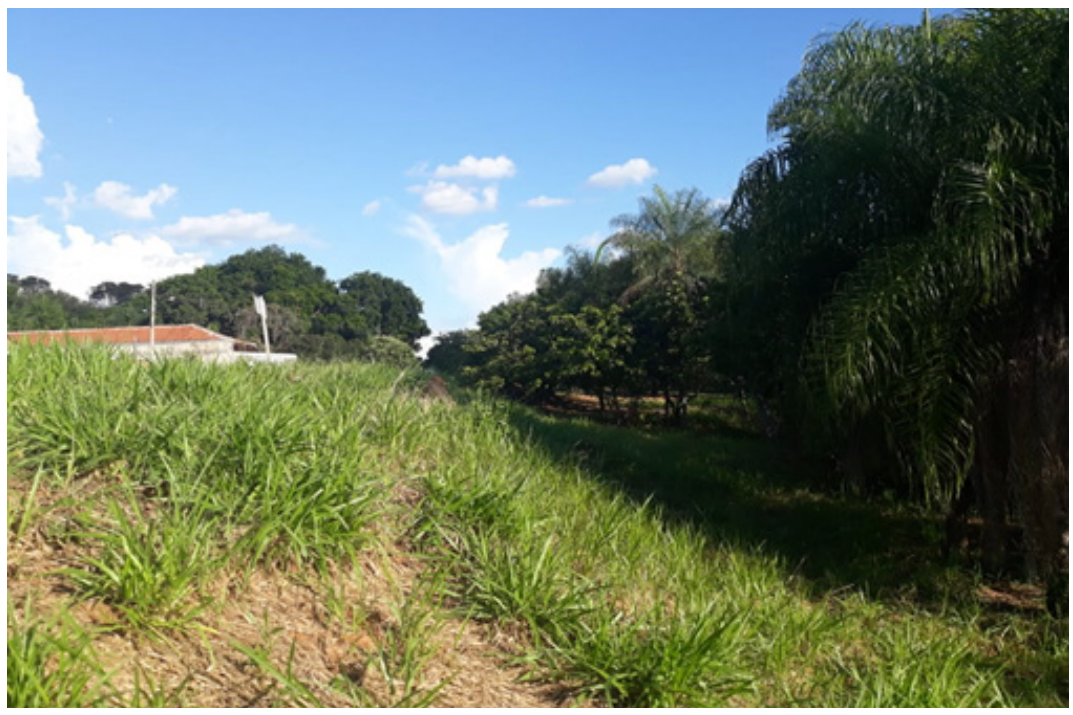

Fonte: Elaboração própria. 
O ideal para esta área é a elaboração de uma trilha e adicionar espécies de árvores frutíferas nativas de porte baixo (Figura 9).

Figura 9 - Ilustração da trilha

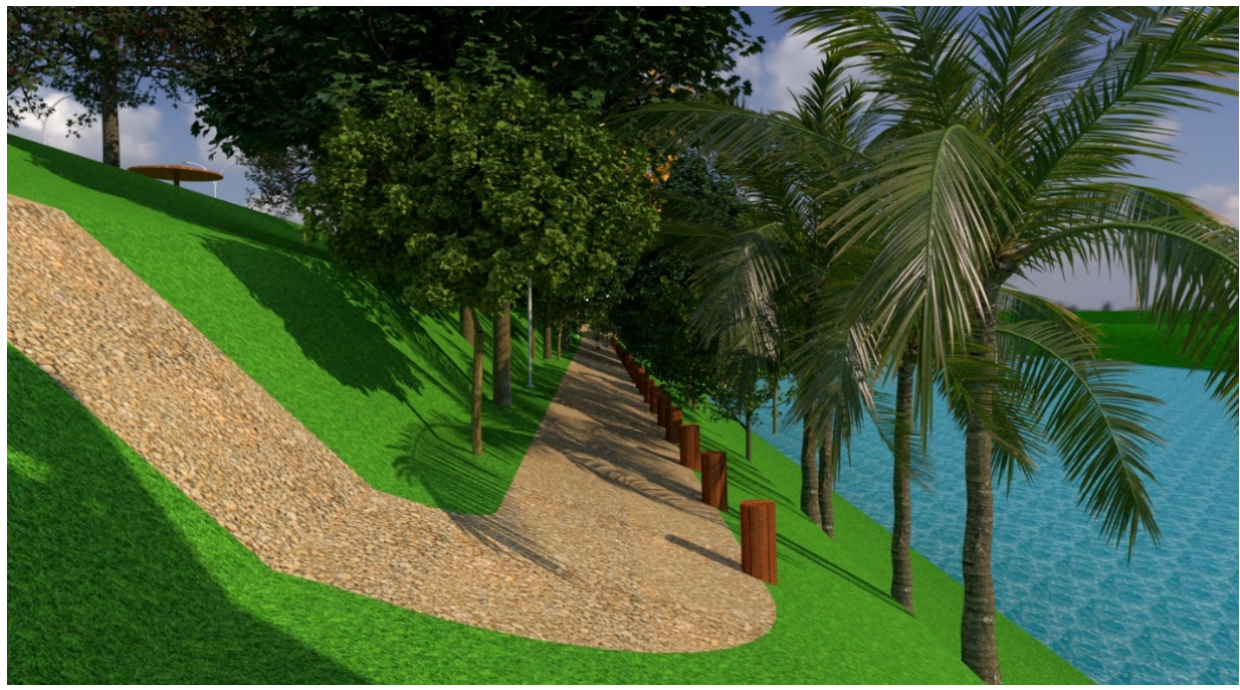

Fonte: Elaboração própria.

Área D - Inicia-se no final da trilha da Área C, não possuindo forrageiras, porém existem cerca de 15 árvores de porte médio a alto, diferindo-se em três espécies de árvores nativas: ciriguela (Spondias purpurea); ingá (Inga diversas); e goiaba (Psidium guajava). A área possui um pequeno trecho de declive que dá acesso ao rio, e seu limite final é a casa de um morador (Figura 10). 
Figura 10 - Área D

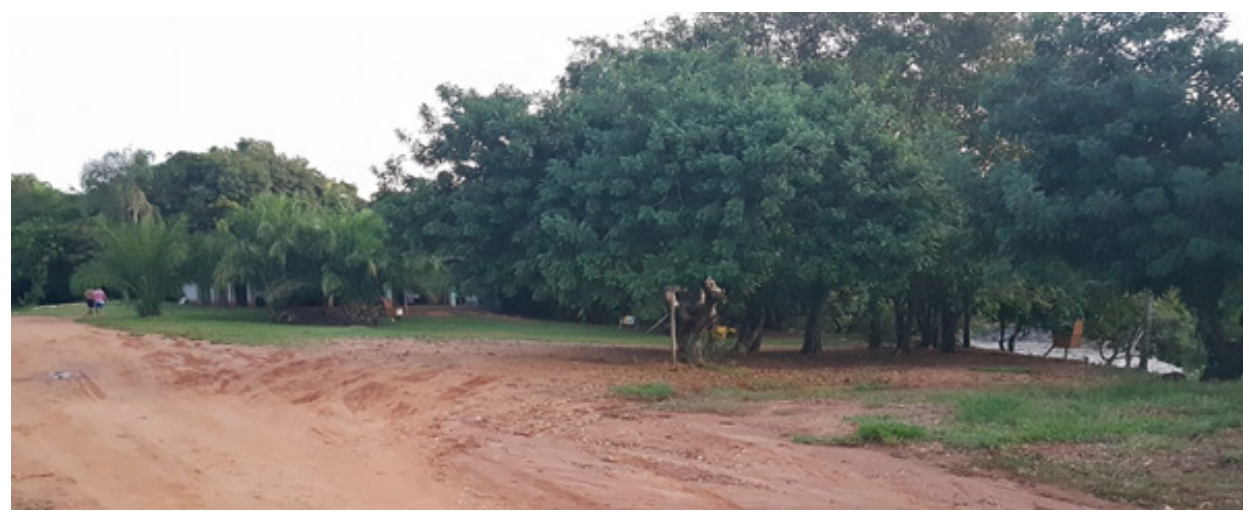

Fonte: Elaboração própria.

Pretende-se adicionar quiosques, área de banho e outro playground infantil, além de mais árvores de porte alto, para que a comunidade possa aproveitar melhor o espaço (Figura 11).

Figura 11 - Ilustração do quiosque e do playground

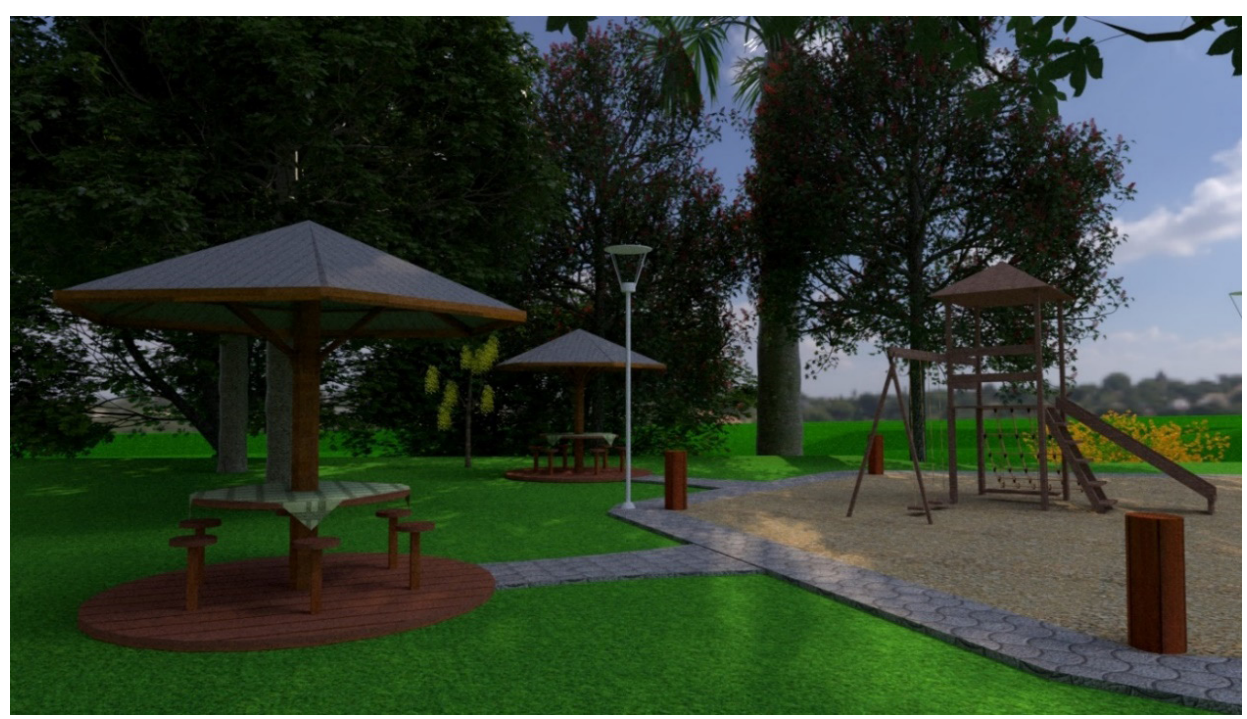

Fonte: Elaboração própria. 
Recuperação e revitalização de área de preservação permanente com projeto de parque linear na cidade de Rochedo, MS: estudo de caso

\subsubsection{Equipamentos e estruturas de lazer}

Para criar um local com atividades atrativas à população, pensou-se em diferentes formas de lazer, sendo elas: lazer recreativo, esportivo e contemplativo, para que assim se consiga atingir uma ampla faixa etária.

Para momentos de recreação, serão adicionados quiosques de sapé com mesas e bancos de madeira para acomodar melhor os visitantes; próximo a eles, haverá um playground para as crianças, de forma que os responsáveis consigam supervisioná-las tranquilamente.

O ambiente será composto por um calçadão para caminhadas e uma ciclovia, um ao lado do outro, sendo sua extensão de uma extremidade à outra do parque. Além disso, haverá uma trilha que dará acesso ao rio, na qual será possível realizar atividades físicas e aumentar o contato com a natureza.

O deck contemplativo de madeira tem como intuito transmitir ao visitante apreço ao lugar, abreviando atos de depredação, para promover prazerosos momentos com sensação de bem-estar (SÁ, 2009). Existirão vários bancos também pelo parque, com a intenção de proporcionar à população momentos de relaxamento e contemplação da natureza.

O parque será composto por uma estrutura de iluminação, com a finalidade de proporcionar maior segurança aos moradores e para que seja possível aproveitar o ambiente após o escurecer, oferecendo, assim, maior tempo de utilização do local. Para conforto e comodidade, serão adicionados banheiros e áreas de banho, que estarão fora da margem de 15 metros do curso d'água, conforme determina a lei.

\subsubsection{Paisagismo}

As espécies foram definidas conforme clima (temperatura e pluviosidade), tipo de bioma e insolação das áreas - baseando-se no Norte do mapa, estabeleceu-se que a margem direita do rio está ao lado leste, recebendo, portanto, a maior parte do sol da manhã; e a parte esquerda está no lado Oeste, obtendo a maior parte do sol da tarde. O lado Norte é classificado como uma zona quente e o Sul como zona fria, em função das correntes 
de ventos dominantes. Desta forma, podemos escolher as plantas que se adaptem melhor a cada ambiente.

É fundamental utilizar espécies nativas, pois, ao introduzir uma espécie exótica em um ambiente a que ela se adapte e não tendo inimigos naturais, essa se reproduzirá em proporções de ocupar o lugar da nativa, alterando a biodiversidade e os processos ecológicos naturais, com tendência de se tornar dominante (ZILLER; ZENNI; GRAF NETO, 2004).

Devem ser tomadas algumas precauções para segurança dos visitantes, de maneira que as espécies não sejam capazes de causar alergia; não tenham flores ou frutos tóxicos nem galhos que caiam com facilidade ou raízes expostas; apresentem troncos lisos e sem espinho. Já as frutíferas não devem ter frutos grandes nem atrair insetos. Além disso, devem-se priorizar as espécies que se encaixarem melhor no uso de cada área do parque, como o passeio, playground, entre outros.

Optou-se, então, por árvores nativas do bioma Cerrado e árvores de biomas diferentes; plantas ornamentais; e árvores frutíferas que, além de alimentar o ser humano, tem grande função no desenvolvimento crescente da biodiversidade do parque e da alimentação animal (VIANI; RODRIGUES, 2005).

\subsubsection{1 Árvores nativas do Cerrado e de outros biomas}

As espécies escolhidas se enquadram nos requisitos mínimos. Priorizamos aquelas com maior floração e frutos atrativos ao ser humano e à fauna.

Árvores nativas do bioma Cerrado: ipê-amarelo (Handroanthus albus); jacarandá-do-mato (Machaerium villosum); araçá-amarelo (Psidium cattleianum); figueira-do-cerrado (Ficus guaranitica); acerola (Malpighia emarginata); baru (Dipteryx alata); flamboyant (Delonix regia);

Árvores nativas de outros biomas: manacá-da-serra (Tibouchina mutabilis); pitangueira (Eugenia uniflora L); jabuticaba (Plinia cauliflora); amora-preta (Rubus Cf brasiliensis); grumixama (Eugenia brasiliensis); mandiocão (Didymopanax morototoni); ipê-mirim (Tecoma stans). 


\subsubsection{Plantas ornamentais}

As plantas ornamentais serão utilizadas para fins decorativos e foram escolhidas conforme a insolação de cada área. Alguns cuidados devem ser tomados na escolha, como: buscar harmonia entre as espécies e na forma da sua distribuição (linha, triângulos dispostos em curvilínea, triângulo com formas iguais, quadrados, entre outros), bem como na forma de posicioná-las nos melhores locais.

As espécies escolhidas conforme a insolação são:

Sol pleno: orquídea-bambu (Arundina graminifolia); cicas (Cycas revoluta); Buxinho (Buxus sempervirens); ixora (Ixora chinensis); heliconia (Heliconia rostrata).

Meia-sombra: copo-de-leite (Zantedeschia aethiopica Spreng); bromélia (Guzmania sp); Alpínia (Alpinia purpurata); lírio-da-paz (Spathiphyllum wallisii); moreia (Dietes bicolor).

Sombra: chuva-de-ouro (Oncidium varicosum).

\subsubsection{Projeto paisagístico}

Neste estudo, foi possível elaborar a planta baixa do projeto, que demonstra a vista com um olhar para baixo, observando-se a distribuição das estruturas e da vegetação. 
Figura 12 - Planta baixa do projeto paisagístico

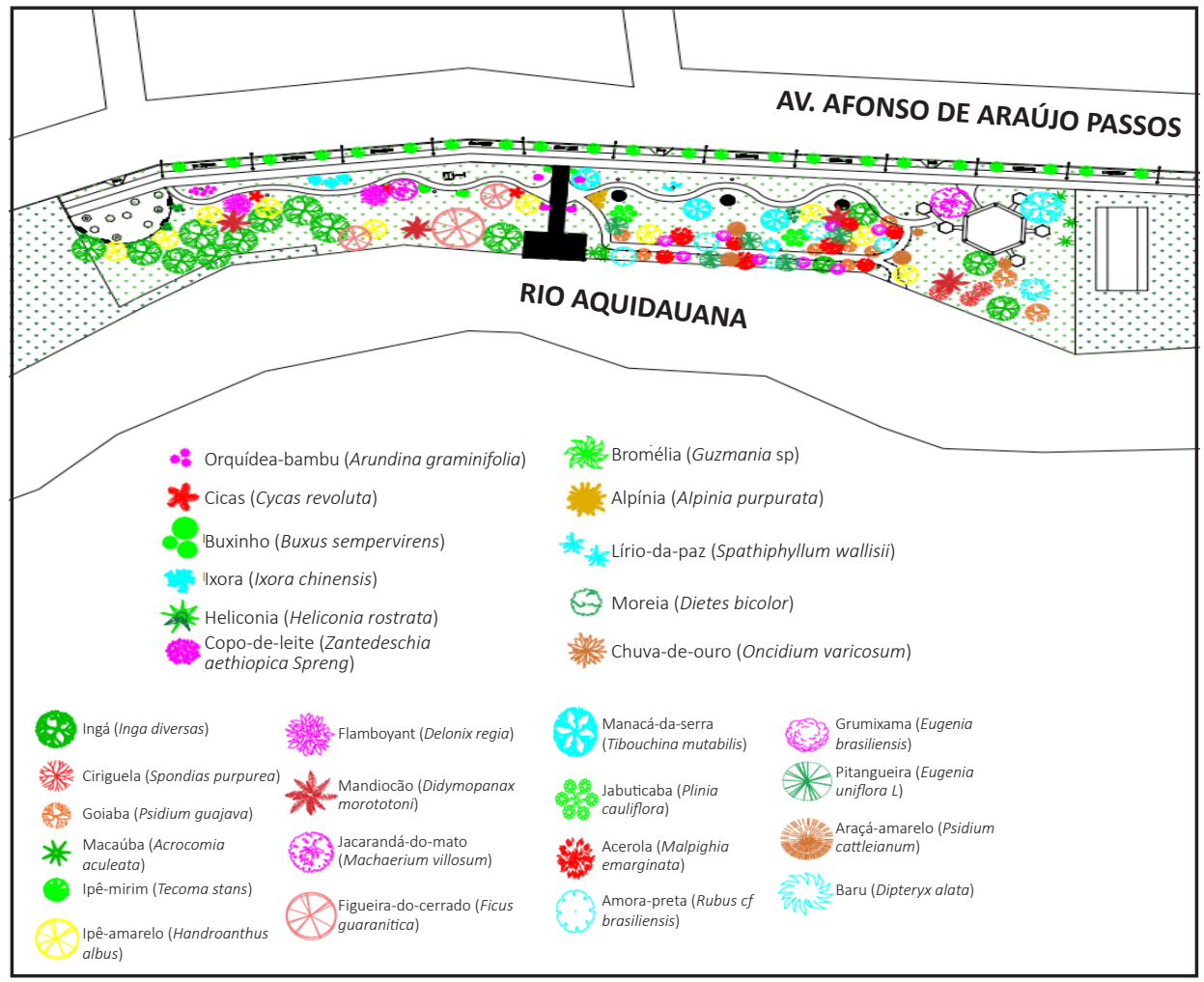

Fonte: Elaboração própria.

\section{CONSIDERAÇÕES FINAIS}

De acordo com o presente estudo, entende-se que o projeto de parque linear suprirá a degradação causada nas áreas de preservação permanente, devido ao não planejamento da cidade de Rochedo, e trará inúmeros benefícios não só ao meio ambiente como também para a qualidade de vida de seus moradores. O projeto está em conformidade com a legislação para evitar maiores danos à APP e, além disso, ser bem aproveitado pela comunidade. 
Recuperação e revitalização de área de preservação permanente com projeto de parque linear na cidade de Rochedo, MS: estudo de caso

\section{REFERÊNCIAS}

ARAÚJO, Suely Mara Vaz Guimarães de. As áreas de preservação permanente e a questão urbana. Brasília, DF: Câmara dos Deputados, Consultoria Legislativa, 2002.

BRASIL. Lei n. 12.651, de 25 de maio de 2012. Novo Código Florestal. Disponível em: http://www.planalto.gov.br/ccivil_03/_ato2011-2014/2012/lei/l12651.htm. Acesso em: 13 fev. 2019.

CARVALHO, Isabel Cristina de Moura. Educação ambiental: a formação do sujeito ecológico (livro eletrônico). São Paulo: Cortez, 2017.

CAVALHEIRO, Felisberto; NUCCI, João Carlos; GUZZO, Perci; ROCHA, Yuri Tavares. Proposição de terminologia para o verde urbano. Boletim Informativo da SBAU, Rio de Janeiro, v. 7, n. 3, p. 7, jul./set. 1999.

COSTA, Renata Geniany S.; BENACHIO, Marcus Vinicios; BORGES, Adairlei Aparecida da S.; COLESANTI, Marlene T. M. Uso, afetividade e percepção: um estudo da satisfação dos frequentadores do Parque do Sabiá em Uberlândia-MG. Revista de Geografia, Recife-PE, v. 28, n. 1, p. 14-24, 2011.

COSTA, Renata Geniany Silva; COLESANTI, Marlene Muno. A contribuição da percepção ambiental nos estudos das áreas verdes. Ra'ega - O Espaço Geográfico em Análise, Curitiba, PR n. 22, p. 238-51, 2011.

GIACOMELLI, Bruna; FREITAS, Matheus Lopes de; PRETO, Graciela Sônego. Proposta paisagística para o município de Cruz Alta/RS: Parque Recanto das Espécies. Revista GEDECON-Gestão e Desenvolvimento em Contexto, Cruz Alta, RS, v. 5, n. 1, p. 98101, 2017.

LONDE, Patrícia Ribeiro; MENDES, Paulo Cezar. A influência das áreas verdes na qualidade de vida urbana. Hygeia - Revista Brasileira de Geografia Médica e da Saúde, Uberlândia, MG, v. 10, n. 18, p. 264-72, jun. 2014.

MATTOS, Ana D. M. de; JACOVINE, Laércio A. G.; VALVERDE, Sebastião R.; SOUZA, Agostinho L. de; SILVA, Márcio L. da; LIMA, João E. de. Valoração ambiental de áreas de preservação permanente da microbacia do Ribeirão São Bartolomeu no município de Viçosa, MG. Revista Árvore, Viçosa, MG. v. 31, n. 2, p. 347-53, 2007.

RIBEIRO, José Felipe; SANO, Sueli Matiko; MACEDO, Jamil; SILVA, José Antônio. Os principais tipos fitofisionômicos da região dos cerrados. Brasília, DF: Embrapa-CPAC, 1983. (Boletim de Pesquisa, 21). 
RIBEIRO, José Felipe; WALTER, Bruno Machado Teles. As principais fitofisionomias do bioma Cerrado. In: SANO, Sueli Matiko; ALMEIDA, Semíramis Pedrosa de; RIBEIRO, José Felipe (Ed.). Cerrado: ecologia e flora. Brasília, DF: Embrapa, 2008. V. 1, p. 151-212.

ROCHEDO (MS). Lei Complementar n. 34, de 24 de novembro de 2014. Plano Diretor de Rochedo/MS. Disponível em: https://leismunicipais.com.br/planodiretor-rochedo-ms. Acesso em: 5 mar. 2019.

SOUSA NETO, Eloi José de; COSTA, Gilvan Gonçalves da. Educação ambiental e a polícia militar: sob a perspectiva de atuação nas escolas públicas e privadas. Biblioteca Digital de Segurança Pública, Goiás, p. 1-18, 2019.

VIANI, Ricardo A. G.; RODRIGUES, Ricardo R. Plantas frutíferas nativas do Brasil: importância, usos e diversidade de espécies. Plantas, Flores e Jardins, São Paulo, p. 50-7, 5 out. 2005. Disponível em: http://www.lerf.eco.br/img/ publicacoes/2005_12\%20arvores\%20frutiferas\%20nativas\%20do\%20Brasil.pdf. Acesso em: 24 jan. 2020.

ZILLER, Sílvia R.; ZENNI, Rafael D.; GRAF NETO, Joachim. Invasões biológicas: introdução, impactos e espécies invasoras no Brasil. In: PEDROSA-MACEDO, José Henrique; BREDOW, Edgard Alfredo. Princípios e rudimentos do controle biológico de plantas: coletânea. Curitiba: UFPR, 2004. p. 17-41. 